\section{Therapeutic Use Exemptions (TUEs) are essential in sport: but there is room for improvement}

\author{
Ken Fitch
}

\section{WHAT IS THE ISSUE?}

Hacking of the World Anti-Doping Agency's (WADA's) Anti-Doping Administrative \& Management System (ADAMS) by an alleged Russian cyber espionage group 'Fancy Bear' disclosed incomplete information about Therapeutic Use Exemptions (TUEs) granted to more than 100 Olympic athletes from over 20 countries $^{1}$ including some high-profile athletes. These unethical and illegal leaks of personal medical information provoked some criticism of the TUE system, much of it is ill-informed. ${ }^{23}$ In this discussion, I briefly review the concept of TUEs and advise how the TUE system can and should be strengthened.

\section{IS THERE A PROBLEM? YES AND NO}

The TUE concept is both sound and essential, and the four criteria that must be met to approve a TUE have changed only marginally in 25 years $^{4}$ (online appendix 1a).

After WADA approved the TUE guidelines in 2004 (that the IOC had adopted in 1991), WADA developed TUE Physician Guidelines - a valuable resource that currently outlines 19 of the different medical conditions that may necessitate an application for a TUE. ${ }^{5}$ These are updated regularly. TUEs are required to be uploaded onto ADAMS and are then reviewed by WADA's Medical Director and the TUEExpert Group (TUE-EG). Via its medical department and TUE-EG, WADA has the capacity to reject or appeal to Court of Arbitration for Sport (CAS) a granted TUE if they deem that it fails to meet the approval criteria.

The recent additional amendment to WADA guidelines that allows retroactive approvals of TUEs via four different avenues has resulted in some controversy. ${ }^{4}$ The competence of some TUE Committees (TUECs) has also been questioned with several instances of inappropriately approved TUEs (online appendix $1 \mathrm{~b}, \mathrm{c})$. An interesting paper detailed the attitudes of 645 Danish athletes towards TUEs with 19\% of respondents having been granted a TUE. A disturbing finding was that

Correspondence to Dr Ken Fitch, Faculty of Human Sciences - Sport, Exercise and Health, University of Western Australia, Crawley, WA 6009, Australia; ken.fitch@uwa.edu.au
$51 \%$ of athletes considered that teammates had received a TUE without medical need. Is this a global view or one held only by Danish athletes? ${ }^{6}$

\section{HOW TO IMPROVE THE RELIABILITY AND STANDARDISATION OF TUEC}

There is a need to ensure that TUECs are comprised of competent persons with appropriate knowledge and experience and that the Committee's modus operandi is functional and acceptable. To achieve this, I recommend that WADA implement an accreditation system for all TUECs with emphasis on the qualifications and experience of TUEC members and examine carefully how each TUEC undertakes its tasks. This should include TUECs established by International Federations (IFs), National Anti-Doping Organisations (NADOs), major games organisations and TUECs established for profit by International Doping Tests and Management, which service sports without appointed TUECs, such as tennis. It would operate somewhat similarly to WADA's Laboratory Accreditation System. ${ }^{7}$ If these appointments and any Committee's modus operandi do not meet the International Standard for TUEs (ISTUEs), ${ }^{4}$ that TUEC should not be accredited by WADA (and therefore be unable to approve TUEs) until it does.

Either that task would need to be undertaken by another WADA-accredited TUEC or the non-accredited TUEC could assess TUE applications but all decisions would need to be approved by WADA's Medical Director. This would be somewhat similar to what occurs when a laboratory loses its WADA accreditation. The role of accrediting TUECs should be undertaken by WADA's Medical Department assisted by its TUE-EG. This will require WADA to better staff and fund its medical department.

\section{ENSURING ALL TUES MEET THE} CRITERIA NECESSARY FOR APPROVAL

For TUEs to meet the approval criteria demands constant and prompt reviewing of all TUEs by WADA. In 2017, there were 3563 approved TUEs notified on ADAMS, which comprise only some of the TUEs approved globally (WADA Medical
Department advice September 2018). This workload places significant strains on WADA's small medical department and poses problems for adequate scrutiny and oversight. However, a significant number of ADOs, both IFs and NADOs, do not upload their TUEs onto ADAMS, which denies WADA ready access to review them. This aspect needs to be addressed.

Critically reviewing the four criteria in the ISTUEs, I conclude that all remain valid and appropriate but the first three are the most crucial. Criterion 1 necessitates that the prohibited medication is essential for treatment and the athlete's health would be affected if it were denied. Criterion 3 requires that there is no permitted alternative to manage the athlete's medical condition. Criterion 2 is the most difficult for TUECs as it states that prohibited drug is highly unlikely to result in any enhancement of performance beyond that achieved by restoring the athlete's health to normal. Ensuring 'a level playing field' is a fundamental principle of antidoping and we should never forget those years of systematic doping and sporting successes by athletes of the German Democratic Republic who denied so many clean athletes a fair chance of Olympic medals ${ }^{8}$ (online appendix 1d).

Contributors I am the sole author and have not collaborated with any other person. I have not sought or needed funding to prepare this paper, which has been undertaken during the past three weeks.

Competing interests The author was chair of the TUEC of the International Olympic Committee 1992-2012, Australia 1992-2014 and WADA's ad hoc group that established the first ISTUEs 2001-2003. He continues to provide advice for several of the medical conditions included in WADA's Medical Information for TUECS.

Patient consent for publication Not required.

Provenance and peer review Not commissioned; externally peer reviewed.

(C) Author(s) (or their employer(s)) 2020. No commercial re-use. See rights and permissions. Published by BMJ.

- Additional material is published online only. To view, please visit the journal online (http://dx.doi.org/ 10.1136/bjsports-2018-100113).

$$
\text { A) Check for updates }
$$

To cite Fitch K. Br J Sports Med 2020;54:191-192.

Accepted 9 April 2019

Published Online First 18 April 2019

Br J Sports Med 2020;54:191-192.

doi:10.1136/bjsports-2018-100113

\section{ORCID iD}

Ken Fitch http://orcid.org/0000-0003-1303-0535

\section{REFERENCES}

1 World Anti-Doping Agency. Wada confirms attack by Russian cyber espionage group. Available: https:// 
www.wada-ama.org/en/media/news/2016-09/wadaconfirms-attack-by-russian-cyber-espionage-group [Accessed Sep 2018].

2 Pitsiladis Y, Wang G, Lacoste A, et al. Make sport great again: the use and abuse of the therapeutic use exemptions process. Curr Sports Med Rep 2017;16:123-5.

3 Gerrard D, Pipe A. Therapeutic use Exemptions. Med Sport Sci 2017;62:55-67.
4 World Anti-Doping Agency. Therapeutic use exemptions, 2016. Available: https://www.wada-ama. org/sites/default/files/resources/files/wada-2016istue-final-en_0.pdf [Accessed Sep 2018].

5 World Anti-Doping Agency. Medical information to support the decisions of TUECS (20). Available: https://www.wada-ama.org/en/resources/search?f\% $5 \mathrm{~B} 0 \% 5 \mathrm{D}=$ field resource collections $\% 3 \mathrm{~A} 158$

6 Overbye M, Wagner U. Between medical treatment and performance enhancement: an investigation of how elite athletes experience therapeutic use Exemptions. Int J Drug Policy 2013;24:579-88.

7 World Anti-Doping Agency. International standard for laboratories (ISL). Available: https://www.wada-ama. org/en/resources/laboratories/international-standardfor-laboratories-is|

8 Franke WW, Berendonk B. Hormonal doping and androgenization of athletes: a secret program of the German Democratic Republic government. Clin Chem 1997:43:1262-79. 